Çukurova Üniversitesi Mühendislik Mimarlık Fakültesi Dergisi, 35(4), ss. 1047-1057, Aralık 2020

Çukurova University Journal of the Faculty of Engineering and Architecture, 35(4), pp. 1047-1057, December 2020

\title{
Bitümlü Sıcak Karıșımlarda Kireçtaşı ve Volkanik Cüruf Filler Kullanımının Dayanıma Etkisinin Araştırılması
}

\author{
Nur Erdem AKGÜL ŞEKER*1, Ali SARIIŞIK ${ }^{1}$ \\ ${ }^{1}$ Harran Üniversitesi, Mühendislik Fakültesi, İnşaat Mühendisliği Bölümü, Şanlıurfa
}

Geliş tarihi: $28.11 .2020 \quad$ Kabul tarihi: 30.12 .2020

$\ddot{O ̈ z}$

Bu çalışmada karayollarında sıklıkla kullanılan bazalt, kaba-ince agrega ve kontrol filler olarak kullanılmıştır. Alternatif filler malzemesi olarak kalker ve volkanik cüruf kullanılmıştır. Agregalara fiziksel, kimyasal ve mekanik özellik tayini yapıldıktan sonra uygun gradasyonda \%4,5, 5, 5,5, 6, 6,5 oranlarında bitüm kullanılarak Marshall stabilite deneyi yapılmıștır. Her bitüm yüzdesinde 3 numune olmak üzere toplam 45 numune döküm yapılmıştır. Optimum bitüm yüzdesi belirlendikten sonra bazalt, kalker ve volkanik cüruf fillerin kullanıldığı numuneler karayolları teknik şartnamesine göre kıyaslanmıştır. Çalışma sonucunda kalker fillerin, optimum bitüm oranını düşürmesi, metilen mavisi deney sonucuna göre sınır değeri aşmaması ve bölgede kalker ocaklarının çok sayıda bulunması nedeniyle alternatif filler olarak kullanılabileceği saptanmıştır.

Anahtar Kelimeler: Marshall stabilite, Filler, Bitümlü sıcak karışım, Bazalt, Kireçtaşı

\section{Investigation of the Effect of Using Limestone and Volcanic Slag Filler on Strength in Hot Bituminous Mixtures}

\begin{abstract}
In study, basalt, which is frequently used in highways, was used as coarse-fine aggregate and control filler. Limestone and volcanic slag were used as alternative filler materials. After determining the physical, chemical and mechanical properties of the aggregates, Marshall stability test was carried out using bitumen at the rate of 4,5, 5, 5,5 6, 6,5\% in appropriate gradation. A total of 45 samples were casted as 3 samples per bitumen percentage. After determining the optimum bitumen percentage, used samples basalt, limestone and volcanic slag were compared according to the highway technical specifications. As a result of the study, it was determined that limestone fillers can be used as alternative fillers because they reduce the optimum bitumen rate, do not exceed the limit value according to the methylene blue test result and there are many limestone quarries in the region.
\end{abstract}

Keywords: Marshall stability, Filler, Bituminous hot mix, Basalt, Limestone

\footnotetext{
*Sorumlu yazar (Corresponding author): Nur Erdem AKGÜL ŞEKER, nurerdema@gmail.com
} 


\section{GíRiș}

Tarihte nüfusun artması ve gelişen teknoloji beraberinde gelen ticaret hacminin artmasiyla yolların gelişimi arttırmıştır [1]. İnsanoğlu MÖ 4000'li yıllarda ilk yolları taş yol olarak yapmıştır [2]. Artan nüfus ve gereklilikler yol ağlarının ve yol performansının geliştirilmesi gerekliliğini ortaya koymuştur.

Güvenli ve konforlu bir ulaşım için gelen trafik yüklerinin zemine güvenle aktarılmasında üstyapı tipi seçimi etkilidir [3-5]. Trafik yüklerine doğrudan maruz kalan üstyapı kaplamaları; yüzeyde bulunan suların drenajını alt tabakalara geçirmeden sağlamalı, aşındırıcı etkilere dayanmalı, kayma ve basınç gerilmelerini zemine güvenle iletmeli, güvenli-konforlu sürüş sağlamalıdır [6]. Bitümlü sıcak karışımlarda yolun üst tabakası için dayanım ve çevre etkilerine karşı dayanıklılı̆̆ sağlayan element, kaplamanın \%90-95'ini olușturan agregalardır [7,8]. Esnek üstyap1 malzemelerinden bitüm yaklaşı $\% 5$ oranında kullanılarak, kaplamayı çevre etkilerden korur, agregaları bir arada tutar ve pürüzsüz yüzey oluşturarak konforlu sürüşü sağlamaktadır. Agregalar ise gelen trafik yüklerini karşılayarak güvenli şekilde zemine iletir $[9,10]$. Yol yapımında kullanılan malzemelerin performans düşüklüğü, yolun servis ömrünü de azaltmaktadır. Servis ömrü malzemeye bağli olarak bitüm ve agrega cinsi ve miktarına göre değişmektedir. Agrega dizaynı; uygulamaya bağlı olarak karıştırma süresi ve sıcaklığı, sıkıştırma gibi birçok etkiye bağlıdır $[11,12]$.

Uygun gradasyondaki agrega ve uygun miktardaki bitümün karıștırılmasıyla olușturulan bitümlü sıcak karışımlar (BSK), trafik yüklerini karşılamalı ve iklim şartlarından en az derecede etkilenmelidir. BSK kaplamanın taşıtlardan gelen statik ve dinamik yükleri karșlayarak yüksek stabilite göstermesi beklenir. Ayrıca uzun ömür için esneklik, geçirimsizlik, işlenebilirlik ve yüksek yorulma mukavemeti de beklenir [13]. Kaplama aynı zamanda güvenli sürüş için uygun kayma direncine sahip olmalı, agregaların yüksek cilalanma derecesine sahip olması beklenir [14].
Agregada bulunan minerallerin sertliği ve porozite de cilalanmayı etkilemekte ve yolun kayma direncini de etkileyen bir etkendir [15-17]. Yapılan araştırmada trafik kazaları ve kayma direnci arasındaki ilişki incelendiğinde, kayma direncinin $\% 13$ artmasıyla kazaların \%60 azaldığı sonucuna varılmışıtır [18].

Yol ağlarının gelişmesi gerekliliği, yol performansını arttırmadaki çalışmaların da önemini arttırmıştır. Araştırmacılar, birçok atık madde ve modifiye edilmiş bitümü kullanarak yol üstyapısını geliştirmeyi hedeflemiştir. Ishai ve ark. [19]; dolomit, kumtaşı, bazalt, cam parçacıkları, kireçtaşı ve hidrate kireci filler malzemesi olarak kullanıp, bitümlü sıcak karışımlarda filler sinıflandırma yaparak fillerin temel özelliklerini incelemişlerdir. Shahrour ve Saloukeh [20], yaptığı çalışmada çimento, hidrate kireç ve sodyum silikatı filler malzeme olarak kullanıp, karışıma bitüme ağırlıkça $\% 0,5$ ve $\% 1,5$ oranlarında ekleme yapmıştır. Filler oranı arttıkça yumuşama noktası ve penetrasyon indeksinin $\operatorname{artt} \breve{g} 1$ ancak penetrasyon değerinin düştüğü sonucuna varmışlardır. Nan $\mathrm{Su}$ ve Chen [21], \%5, \%10 ve $\% 15$ oranlarında cam atığını bitümlü karışımlara katarak, atık kullanılmayan karışımların stabilite, nem ve kayma özelliklerini incelemişlerdir. Marshall stabilite deneyi sonucunda cam atığının uygun oranda kullanılabileceğini bildirmişlerdir. Yllmaz ve Kök [22], ferrokrom cürufunun bitümlü sıcak karışımlarda agrega olarak kullanılabilirliğini araştırmıştır. Ferrokrom cürufunun modifiyeli bitümle birlikte kullanılmasının mekanik özelliklerini incelemiştir. Ferrokrom cürufunun iyi performans verdiği ve modifiye bitümün performansı arttırdığ 1 sonucuna varılmıştır. Arabani ve Mirabdolazimi [23], bitümlü sıcak karışımlarda demir tozunu kullanarak, karışımın çekme mukavemeti performansını incelemişlerdir. Çalışma sonucunda demir tozunun karışımda yorulma ömrünü uzattığı bildirilmiştir. Mazlum [24], yaptığı çalışmada İstanbul çevresinde yol ömrünü tamamlamış yolları \%10, 25, 40 oranlarında kullanarak yeni numunelere Marshall stabilite deneyi uygulamıștır. Elde edilen bulgular katkısız numunelerle karşılaştırılıp, ekonomik 
katkılar değerlendirilmiştir. Morova ve Terzi [25], yaptıkları çalışmada kolemanit atıklarının bitümlü karışımlarda kullanılabilirliğini dört farklı agrega ile araştırmışlardır. Çalışma sonucunda en iyi performansı kireçtaşı gösterirken, KGM Teknik Şartname değerlerine sadece kolemanit ve kireçtaşı uygunluk göstermiştir. Nabiun ve Khabiri [26], yaptığı çalışmada ferritin filler malzeme olarak kullanılabilirliğini ve karışımın nem hassasiyetini araştırmışlardır. Farklı oranlarda kullanılan ferrit, kalkerin kullanıldığı numunelerle kıyaslanmıştır. Deney sonucunda, ferritin bitümlü karışımlarda yüksek oranda kullanılması durumunda etki ettiği görülmüştür. Keskin ve Karacasu [27], çalışmada $1,18 \mathrm{~mm}$ 'lik eleğin altında kalan bor atıklarını $\% 5$, $\% 10$ ve $\% 15$ oranlarında kullanarak toplam 170 adet bitümlü sıcak karışım numuneleri oluşturmuştur. Deney sonucunda, bor mineralinin optimum bitüm yüzdesini arttırdığı ve karışımlarda kullanılmasının uygun olduğu görülmüştür. Woszuk ve arkadaşları [28] endüstride ciddi bir atık olan uçucu külü, kalker fillerin yerine $\% 25$, $\% 50$ ve $\% 75$ oranlarında ikame etmiştir. Çalışmada iki farklı kül türü kullanılmıştır. Çalışma sonucunda her iki kül türünün de alternatif filler malzemesi olarak kullanılabileceği görülmüştür. Beycioğlu ve arkadaşları [29] çalışmalarında endüstriyel atık olan cam elyaf takviyeli polyester boru atık tozunun bitümlü sıcak karışımlarda filler malzeme olarak kullanılmasını değerlendirmiştir. Atık içeriği \%0, \%25, \%50 ve $\% 75$ olarak belirlenmiştir. Çalışma sonucunda endüstriyel atıkların bitümlü sıcak karışımlarda kullanımının önemi vurgulanmış ve cam elyaf takviyeli polyester boru atığının kullanılabileceğini de belirlemişlerdir. $\mathrm{Bu}$ çalışmada diğer çalışmalardan farklı olarak karayollarında sıklıkla tercih edilen bazalt agregasıyla birlikte filler malzeme olarak kalker ve volkanik cürufun kullanılabilirliği araştırılmıştır.

\section{MATERYAL VE METOT}

\subsection{Materyal}

Ülkemizde 01.01.2020 tarihi itibariyle otoyol, devlet yolu ve il yolu olmak üzere Karayolları
Genel Müdürlüğü (KGM) sorumluluğunda toplam $68.231 \mathrm{~km}$ yol ağır bulunmaktadır. Bunların \%37,7'si asfalt betonu, \%56,89'u sathi kaplamadan oluşmaktadır. Ayrıca toplam $25.705 \mathrm{~km}$ bölünmüş yol ağı bulunmaktadır. Çalışmanın gerçekleştirildiği Şanlıurfa ilinin bulunduğu 9. Bölge Müdürlüğüne ait toplam $4781 \mathrm{~km}$ yol ağı bulunmaktadır.

9. Bölge Müdürlüğü yol ağı haritasında $146 \mathrm{~km}$ otoyol, $2030 \mathrm{~km}$ devlet yolu ve $2605 \mathrm{~km}$ ilk yolu ağ1 KGM sorumluluğundadır. Bölgede toplam $1371,30 \mathrm{~km}$ bölünmüş yol ağı bulunmaktadır. Yol ağlarının \%91'i asfalt kaplama yollardır. Ayrıca Şanlıurfa ilinde KGM sorumluluğunda otoyol, devlet yolu ve il yolu olmak üzere toplam $1350 \mathrm{~km}$ yol ağı bulunmaktadır. Bunların $452 \mathrm{~km}$ 'si asfalt beton, 853 km'si sathi kaplama yollardır [30]. Bölgede bulunan önemli yollar, yol ağı uzunlukları göz önüne alındığında bölgedeki yol performansı geliştirme çalışmaları daha da önem kazanmıştır.

Bu çalışmada ana materyal olarak agrega ve bitüm olmak üzere iki farklı materyal kullanılmıştır. Bazalt, kalker ve volkanik cüruf olmak üzere ise üç farklı doğal agrega kullanılmıştır. Kaba-ince agrega tüm karışımlarda bazalt olarak kullanılmış olup, sadece filler değişken materyal olarak kullanılmıştır. Bölgede çoğunlukla bazaltın kullanılmasından dolayı ise bazalt, kontrol filler olarak değerlendirilmiştir.

Bazalt ve kalkerin ocağı Şanlıurfa İli’nde, volkanik cürufun ise Adıyaman İli'nde bulunmaktadır. Doğal agregaların Şanlıurfa İli'nde ve çevresinde bulunmasına özen gösterilmiştir. Bazalt ve kalker Beltaş A.Ş.'den, volkanik cüruf ise Şanlıurfa Büyükşehir Belediyesi’nden temin edilmiştir.

Çalışmada 50/70 penetrasyonlu bitüm tercih edilmiş olup, Şanlı Asfalt A.Ş.'den temin edilmiştir. İlgili firma ise Batman TÜPRAŞ Rafinerisinden temin ettiğini bildirmiştir.

Çalışmada Karayolları Teknik Şartnamesine uygun, aşınma tabakası tip-1 için belirlenen sınır değerlerde gradasyon oluşturulmuştur. 
Çizelge 1'de verilen aşınma tabakası tip-1 için filler sınır değerleri \%3-8 arasında verilmiş olup, çalışmada \%6 olarak sabit tutulmuştur. Çalışmada filler malzeme değişken olarak kullanılıp, etkisi araştırılmıştır.

Çizelge 1. Aşınma tabakası tip-1 sınır değerleri [31]

\begin{tabular}{|c|c|c|}
\hline $\begin{array}{c}\text { Elek çap1 } \\
(\mathrm{mm})\end{array}$ & $\begin{array}{c}\text { Alt Limit } \\
\text { (\%Geçen) }\end{array}$ & $\begin{array}{c}\text { Üst Limit } \\
\text { (\%Geçen) }\end{array}$ \\
\hline 19,00 & 100 & 100 \\
\hline 12,50 & 88 & 100 \\
\hline 9,50 & 72 & 80 \\
\hline 4,75 & 42 & 52 \\
\hline 2,00 & 25 & 35 \\
\hline 0,425 & 10 & 20 \\
\hline 0,180 & 7 & 14 \\
\hline 0,075 & 3 & 8 \\
\hline
\end{tabular}

\subsection{Metotlar}

Çalışma 3 farklı deney aşamasında gerçekleştirilmiştir. Öncelikle agregalara fiziksel, mekanik ve kimyasal deneyler uygulanmıştır. Daha sonra kullanılan 50/70 penetrasyon bitüme fiziksel özelliklerini belirlemek amacıyla deneyler uygulanmıştır. Özellikleri belirlenen agrega ve bitüm aşınma tabakası tip-1'e uygun gradasyonda karışımlar yapılarak $\% 4,5, \quad 5, \quad 5,5,6, \quad 6,5$ oranlarında bitüm kullanılarak, her karışımdan 3 numune olmak üzere toplam 45 adet numune dökülerek Marshall stabilite deneyine tabii tutulmuştur. Optimum bitüm yüzdesi belirlenen numuneler kontrol filler malzemesi olan bazalt ile karşılaştırılarak kullanılabilirliği değerlendirilmiş̧tir.

Kullanılacak bazalt, kalker ve volkanik cürufun karışımda kullanıldığ yapılmıştır. Özgül ağırlık ve absorbsiyon deneyi [32] kaba ve ince agregada bazalta, filler malzemede bazalt, kalker ve volkanik cürufa uygulanmıştır. Los Angeles aşınma deneyi [33] kaba agrega olan bazalt agregasina, Soyulma mukavemeti deneyi [34] ince agrega olan bazalt agregasına, Slake durabilite deneyi [35] kaba ve ince agrega olan bazalt agregasina, hava tesirlerine karşı dayanım deneyi [36] kaba ve ince agregadan dolayı bazalt agregasına uygulanmıştır. Metilen mavisi deneyi [37] ve X-Işını floresans spektrometresi (XRF) ise bazalt, kalker ve volkanik cüruf agregalarına uygulanmıştır. Sınır değerler için Karayolları Teknik Şartnamesinde uygun görülen değerler baz alınmış olup araştırma bulgularının verildiği bölümde verilmiştir. Slake durabilite katsayısının siniflandırılması Çizelge 2'de verilmiştir.

Çizelge 2. Slake durabilite sinıflaması (\%) [38]

\begin{tabular}{|c|c|c|}
\hline $\begin{array}{c}\text { İndeks } \\
\text { Değeri } \\
\left(\mathrm{I}_{\mathrm{d}-1}\right)\end{array}$ & $\begin{array}{c}\text { Indeks } \\
\text { Değeri } \\
\left(\mathrm{I}_{\mathrm{d}-2}\right)\end{array}$ & $\begin{array}{c}\text { Dağılma } \\
\text { Dayanım } \\
\text { Sinıflamäs }\end{array}$ \\
\hline$<60$ & $0-30$ & Çok düşük \\
\hline $60-85$ & $30-60$ & Düşük \\
\hline $85-95$ & $60-85$ & Orta Derecede \\
\hline $95-98$ & $85-95$ & Orta-Yüksek \\
\hline $98-99$ & $95-98$ & Yüksek \\
\hline$>99$ & $>98$ & Çok Yüksek \\
\hline
\end{tabular}

Kullanılan 50/70 penetrasyonlu bitümün fiziksel özelliklerini belirlemek için KGM Teknik Şartnamesinde de belirtilen belli başlı deneyler uygulanmıştır. 50/70 penetrasyonlu bitüme özgül ağırlık deneyi [39], penetrasyon tayini deneyi [40], yumuşama noktası deneyi [41], parlama noktası deneyi [42], düktilite deneyi [43] uygulanmıştır.

Bitümlü sıcak karışımların uygun gradasyonda karıştırılmasından sonra Marshall stabilite deney aletiyle karışımın akmaya karşı direncinin ölçülmesi gerekir. Bu yöntemde yanal yüzeylere yapılan yükleme sonucu akma değeri elde edilmiştir.

Karayolları teknik şartnamesinde belirtilen aşınma tabakası tip-1'deki aralığa uygun agrega karışımı $1200 \mathrm{~g}$ olacak şekilde hazırlanır ve $105^{\circ} \mathrm{C}$ sıcaklıkta kurutulmuştur. Bitümlü bağlayıcının akışkan olması için $140^{\circ} \mathrm{C}$ sıcaklıktaki etüvde bekletilmiştir. Aynı esnada kullanılacak 4 inç Marshall kalıplar da etüvde bekletilerek 1sıtılmıştır. Uygun sıcaklığa gelen agrega ve bitüm, karıştırma süresi 2 dakikayı geçmeyecek şekilde homojen olarak karıştııılmıştır. Her bitüm yüzdesinden 3 numune hazırlanmıştır. Etüvden alınan kalıplar 
numunenin kolay çıkarılması için yağlanmıştır. Karışım kalıplara 1/3 oranında dökülerek 25 defa şişlenerek sıkıştırılmıştır. Marshall kalıplara doldurulan karışım, her iki yüzüne 25 vuruş olacak şekilde Marshall tokmağında sıkıştırılmıştır. Sıkıştırılan numuneler kalıpların içerisinde 24 saat soğumaya birakılır. 24 saatin sonunda oda sıcaklığına gelen numuneler kriko yardımıyla kalıptan çıkarılmıştır. Numunelere 3 farklı noktadan yükseklik ölçümü yapılır ve aritmetik ortalaması not edilmiştir. $\mathrm{Bu}$ değer, numune için düzeltme katsayısı olarak kullanmak için cihaza girilmiştir. Marshall stabilite deneyinin gerçekleştirilmesi için numuneler $60^{\circ} \mathrm{C}$ sıcaklıktaki suda 30-45 dakika bekletilmiştir. $60^{\circ} \mathrm{C}$ sicaklıktaki sudan alınan numuneler hizlı şekilde diş yüzeyi kurutularak bekletilmeden cihaza yerleştirilmiştir. Şekil 2'de Marshall stabilite ve akma deney cihazına yerleştirilmiş numune görülmektedir.

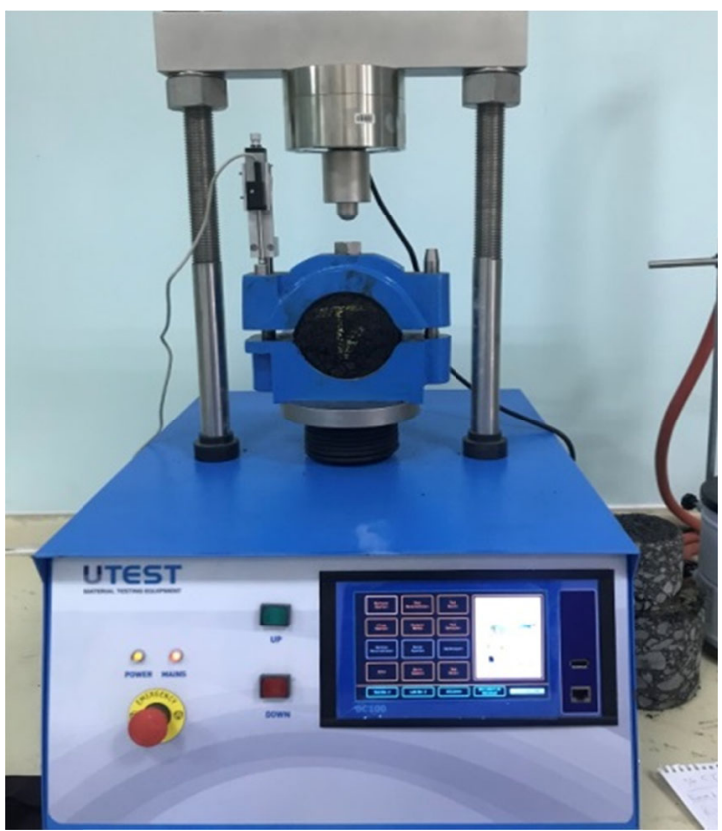

Şekil 2. Marshall stabilite ve akma deney cihazı

Şekil 2'deki Marshall stabilite deney cihazına yerleştirilen numune 1sı kaybetmeden deneyin gerçekleştirilmesi gerekir. Cihazın yük ve akma değerleri sıfırlanır. Numunenin yüksekliği değeri girilen cihaz çalıştırılarak, yanal eksenlerden yük uygulanmaya başlanmıştır. Deney yaklaşık 5-15 saniye aralığında gerçekleştirilmiştir. Cihaz, akma ve stabilite değerini vermiştir. ASTM D6927-15 [44] standardina uygun olarak gerçekleştirilen deney sonunda hesaplamalar yapılmıştır. Bu hesaplamalar y/ardımıyla optimum bitüm yüzdesi elde edilerek dayanımı en iyi, bitüm oranı en uygun olan ekonomik karışım elde edilir.

\section{ARAŞTIRMA BULGULARI VE TARTIŞMA}

\subsection{Agrega Fiziksel, Mekanik ve Kimyasal Özellik Tayini Sonuçları}

Bazalt, kalker ve volkanik cüruf agregalarına kaba, ince ve filler malzeme olarak, standarda uygun gerçekleştirilen özgül ağırlık deney sonuçları Çizelge 3'te verilmiştir.

Karayollarında agregaların uygulanacak deneylerle bazı sınır değerleri aşmaması beklenir. Sınır değerleri aşan agregalar karayolları için uygun görülmez ve kullanılmaz. Çizelge 4'te Karayolları Teknik Şartnamesinde sinır değerleri bulunan deneylerin sonuçları ve sınır değerler bir arada verilmiştir.

Çizelge 3. Özgül ağırlık deney sonuçları

\begin{tabular}{|c|c|c|c|c|}
\hline \multicolumn{4}{|c|}{ Deney Sonuçları $\left(\mathrm{g} / \mathrm{cm}^{3}\right)$} & \multirow{6}{*}{ 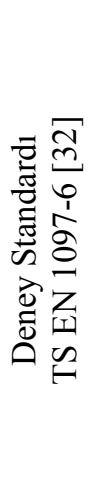 } \\
\hline \multirow{3}{*}{\multicolumn{2}{|c|}{$\begin{array}{c}\text { Kaba Agrega } \\
\text { (Bazalt) }\end{array}$}} & $\begin{array}{l}\text { Hacim özgüll } \\
\text { ağırlık }\end{array}$ & 2,57 & \\
\hline & & $\begin{array}{c}\text { Doygun yüzey } \\
\text { özgül ağırlık }\end{array}$ & 2,63 & \\
\hline & & $\begin{array}{l}\text { Zahiri özgüll } \\
\text { ağırlık }\end{array}$ & 2,75 & \\
\hline \multirow{2}{*}{\multicolumn{2}{|c|}{$\begin{array}{c}\text { İnce Agrega } \\
\text { (Bazalt) }\end{array}$}} & $\begin{array}{l}\text { Hacim özgül } \\
\text { ağırlık }\end{array}$ & 2,70 & \\
\hline & & $\begin{array}{l}\text { Zahiri özgüll } \\
\text { ağırlık }\end{array}$ & 2,86 & \\
\hline \multirow{3}{*}{ 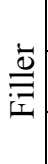 } & Bazalt & \multirow{3}{*}{$\begin{array}{l}\text { Zahiri özgüll } \\
\text { ağırlık }\end{array}$} & 2,57 & \\
\hline & Kalker & & 2,51 & \\
\hline & V. Cüruf & & 2,60 & \\
\hline
\end{tabular}


Çizelge 4. Karayolları Teknik Şartnamesi sınır değerleri olan deneylerin sonuçları

\begin{tabular}{|c|c|c|c|c|c|}
\hline \multicolumn{2}{|c|}{ Deney Adı } & Deney Standard 1 & \multicolumn{2}{|c|}{ Deney Sonucu } & Sinır Değer \\
\hline \multicolumn{2}{|c|}{ Los Angeles Aşınma Deneyi (\%) } & TS EN 1097-2 & \multicolumn{2}{|c|}{18,1} & $\leq 27$ \\
\hline \multirow{2}{*}{ Su Emme (\%) } & Kaba Agrega & \multirow{2}{*}{ TS EN 1097-6 } & & & \multirow{2}{*}{$\leq 2,0$} \\
\hline & İnce Agrega & & \multicolumn{2}{|c|}{2,70} & \\
\hline \multirow{3}{*}{\multicolumn{2}{|c|}{ Metilen Mavisi (\%) }} & \multirow{3}{*}{ TS EN 933-9+A1 } & Bazalt & 2,50 & \multirow{2}{*}{$\leq 3,0$} \\
\hline & & & V.Cüruf & 5,75 & \\
\hline & & & Kalker & 1,50 & $\leq 1,50$ \\
\hline \multicolumn{2}{|c|}{ Soyulma Mukavemeti (\%) } & TS EN 12697-11 & \multicolumn{2}{|c|}{98} & $\geq 60$ \\
\hline \multicolumn{2}{|c|}{$\begin{array}{l}\text { Hava Tesirlerine Karşı Dayanım } \\
\text { Deneyi (\%) }\end{array}$} & TS EN 1367-2 & \multicolumn{2}{|c|}{1} & $\leq 16$ \\
\hline
\end{tabular}

Çizelge 4'te karayolları teknik şartnamesinde sınır değerleri bulunan deneyler incelendiğinde kaba ve ince agregada kullanilan bazalt agregasinın su emme değerinin sınır değeri aştığı görülmektedir. Kullanılan agreganın aşınma tabakası tip-1 için uygun olmadığı sonucuna varılmıştır. Metilen mavisi deneyi incelendiğinde kalker sınırda bulunurken, volkanik cürufun sınır değeri çok fazla aştı̆̆ görülmektedir. Kullanılan bazalt agregası ise metilen mavisi deneyi için belirtilen sınır değerini aşmamıştır.

Suda dağılım deneyi olarak da adlandırılan Slake durabilite deneyi, karayollarında kullanılan bir deney değildir. Agregaların islanma, sıcaklık ve tekrar kuruma etkisiyle yapısında oluşabilecek bozulmaları tahmin etmeye yarar. Karayollarında kullanılan agregaların doğrudan sıcaklık, yağmur ve tekrar kuruma etkisinde kalmasindan dolayı bu deneyi yapma gerekliliği oluşmuştur. Slake durabilite deney sonucu Çizelge 5 'te verilmiştir. Değerlendirme Çizelge 2'yi referans alarak yapılmıştır.

Çizelge 5. Slake durabilite sonuçları

\begin{tabular}{|c|c|c|c|}
\hline \multicolumn{2}{|c|}{$\begin{array}{c}\text { Deney Sonucu } \\
(\%)\end{array}$} & Değerlendirme & \multirow{4}{*}{ 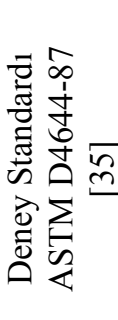 } \\
\hline $\mathrm{I}_{\mathrm{d}-1}$ & 99,71 & Çok Yüksek & \\
\hline $\mathrm{I}_{\mathrm{d}-2}$ & 96,48 & Yüksek & \\
\hline Ortalama & 98,10 & Yüksek & \\
\hline
\end{tabular}

Çizelge 5 incelendiğinde deneyin uygulandığı bazalt agregasının suda çevrim ve daha sonrasında kurulanma durumunda çok yüksek dayanım gösterildiği sonucuna varılmıştır.

Bazalt, kalker ve volkanik cüruf için yapılan XRF analiz sonuçları Çizelge 6'da verilmiştir.

Çizelge 6. Bazalt, kalker ve volkanik cüruf XRF analiz sonuçları (\%)

\begin{tabular}{|l|c|c|c|c|c|}
\hline \multicolumn{2}{|c|}{ Bazalt } & \multicolumn{2}{c|}{ Kalker } & \multicolumn{2}{c|}{ Volkanik cüruf } \\
\hline Bileşen & Sonuç & Bileşen & Sonuç & Bileşen & Sonuç \\
\hline $\mathrm{SiO}_{2}$ & 46,12 & $\mathrm{CaO}$ & 55,31 & $\mathrm{SiO}_{2}$ & 42,89 \\
\hline $\mathrm{Al}_{2} \mathrm{O}_{3}$ & 17,56 & $\mathrm{Ig}$ & 43,40 & $\mathrm{Al}_{2} \mathrm{O}_{3}$ & 18,85 \\
\hline $\mathrm{Fe}_{2} \mathrm{O}_{3}$ & 11,35 & $\mathrm{SiO}_{2}$ & 0,53 & $\mathrm{Fe}_{2} \mathrm{O}_{3}$ & 10,40 \\
\hline $\mathrm{CaO}$ & 11,05 & $\mathrm{MgO}$ & 0,21 & $\mathrm{CaO}$ & 9,19 \\
\hline $\mathrm{Na}_{2} \mathrm{O}$ & 3,95 & $\mathrm{Al}_{2} \mathrm{O}_{3}$ & 0,21 & $\mathrm{Na}_{2} \mathrm{O}$ & 5,45 \\
\hline $\mathrm{MgO}$ & 3,65 & $\mathrm{Fe}_{2} \mathrm{O}_{3}$ & 0,15 & $\mathrm{MgO}$ & 4,31 \\
\hline $\mathrm{TiO}_{2}$ & 2,18 & $\mathrm{SrO} \mathrm{O}$ & 0,06 & $\mathrm{~K}_{2} \mathrm{O}$ & 3,35 \\
\hline $\mathrm{Ig}$ & 1,89 & $\mathrm{P}_{2} \mathrm{O}_{5}$ & 0,03 & $\mathrm{TiO}_{2}$ & 2,45 \\
\hline $\mathrm{K}_{2} \mathrm{O}$ & 1,26 & $\mathrm{SO}_{3}$ & 0,03 & $\mathrm{Ig}$ & 1,21 \\
\hline $\mathrm{P}_{2} \mathrm{O}_{5}$ & 0,35 & $\mathrm{TiO}_{2}$ & 0,02 & $\mathrm{P}_{2} \mathrm{O}_{5}$ & 0,82 \\
\hline
\end{tabular}

Çizelge 6'daki XRF sonuçları incelendiğinde $\mathrm{SiO}_{2}$ bileşeninin bazalt ve volkanik cüruf agregasında fazla bulunduğu görülmektedir. $\mathrm{Bu}$ bileşen dayanımı artırıcı etki gösterse de içeriğinde bulunan $\mathrm{Si}$ elementinin varlı̆g 1 bitümlü karışımlarda soyulmayı artırması nedeniyle katkı madde kullanımı gerektirebilir. Kalkerde bulunan $\mathrm{CaO}$ bileşeni dayanımı artırıcı etki gösterse de yağmur etkisiyle oluşacak ufak bir bozulmada hızlı bir şekilde yaşlanma görülecektir. 


\subsection{Bitümlü Bağlayıcı Fiziksel Özellik Tayini Sonuçları}

Çalışmada kullanılan bitüme çalışmaları kolaylaştırmak ve oluşabilecek kazaları önlemek için bazı deneylerin yapılması gerekir. Çalıșmada bitümlü bağlayıcı özgül ağırlık deneyi, penetrasyon deneyi, yumuşama noktası deneyi, parlama noktası deneyi ve düktilite deneyi yapılmıştır. Deney sonuçları Çizelge 7'de verilmiştir.

Çizelge 7. Bitümlü bağlayıcı fiziksel özellik tayini sonuçları

\begin{tabular}{|l|c|c|}
\hline Deney Adı & Standart & Sonuç \\
\hline Penetrasyon Tayini & TS EN 1426 & 58 \\
\hline $\begin{array}{l}\text { Yumuşama Noktası } \\
\text { Tayini }\left({ }^{\circ} \mathrm{C}\right)\end{array}$ & TS EN 1427 & 53,25 \\
\hline Düktilite Tayini $(\mathrm{cm})$ & TS EN 13589 & $100+$ \\
\hline $\begin{array}{l}\text { Parlama Noktası Tayini } \\
\left({ }^{\circ} \mathrm{C}\right)\end{array}$ & TS EN ISO 2592 & 303,6 \\
\hline Özgül Ağırlık $\left(\mathrm{g} / \mathrm{cm}^{3}\right)$ & TS EN 15326+A1 & 1,04 \\
\hline
\end{tabular}

\subsection{Karışım Gradasyonu ve Marshall Stabilite Deney Sonuçları}

Karayolları teknik şartnamesine uygun olarak tamamlanan agrega ve bitüm deneylerinden sonra sınır değerlere uygun şekilde kullanılacak gradasyon belirlenmiştir. Karışımın aşınma tabakası tip-1 sınır değerleri ve kullanılan gradasyon Çizelge 8'de verilmiştir.

Çizelge 8. Sınır değerler ve kullanılan gradasyon

\begin{tabular}{|c|c|c|c|}
\hline $\begin{array}{c}\text { Elek } \\
\text { çap1 } \\
(\mathrm{mm})\end{array}$ & $\begin{array}{c}\text { Alt Limit } \\
(\% \text { Geçen) }\end{array}$ & $\begin{array}{c}\text { Üst Limit } \\
(\% \text { Geçen })\end{array}$ & $\begin{array}{c}\text { Kullan1lan } \\
\text { Gradasyon } \\
(\%)\end{array}$ \\
\hline 19,00 & 100 & 100 & 100 \\
\hline 12,50 & 88 & 100 & 90 \\
\hline 9,50 & 72 & 80 & 78 \\
\hline 4,75 & 42 & 52 & 45 \\
\hline 2,00 & 25 & 35 & 32 \\
\hline 0,425 & 10 & 20 & 15 \\
\hline 0,180 & 7 & 14 & 8 \\
\hline 0,075 & 3 & 8 & 6 \\
\hline
\end{tabular}

Karayolları teknik şartnamesi aşınma tabakası tip-1 için verilen alt ve üst limit aralığında kalan gradasyon eğrisi Şekil 3 'te verilmiştir.

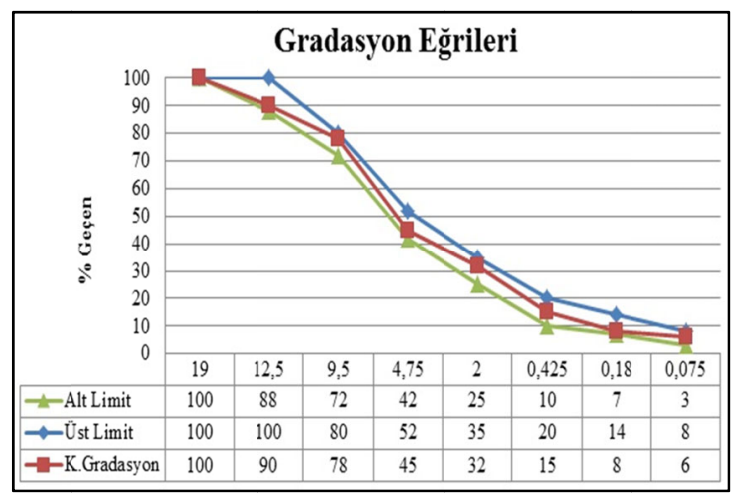

Şekil 3. Gradasyon eğrisi

Şekil 3 incelendiğinde karışımın \%55'i kaba agrega, \%39'u ince agrega ve \%6's1 filler malzemeden oluşmaktadır. Karışım, alt ve üst sınır değerlere uygundur. Her numune 1200 g olacak şekilde uygun yüzdelikllerde numuneler hazırlanmıştır

Gradasyona uygun şekilde toplam $1200 \mathrm{~g}$ olan agregalar etüvde kurutulduktan sonra $\% 4,5,5,5,5$, $6,6,5$ oranlarında bitümün karıştırılmasıyla oluşturulan numuneler soğumaya birakılır. Her bitüm yüzdesinden 3 numune olmak üzere toplam 45 numune dökülmüştür. 30-4.5 dakika aralığında $60^{\circ} \mathrm{C}$ sicaklikta bekletilen numuneler Marshall stabilite deneyine tabii tutulmuştur. Deney sonucunda ilgili işlemler yapıldıktan sonra \%Bitüm-Stabilite,\%Bitüm-Akma, \%Bitüm-Boşluk, \%Bitüm-Hacim özgül ağırlık, \%Bitüm-Bitümle dolu boşluk grafikleri elde edilmiştir. Bu grafikler optimum bitüm yüzdesinin bulunmasında yardımcı olmuştur. İlgili grafikler Şekil 4’te verilmiştir.

Shekil 4'teki \%Bitüm-Stabilite grafiği incelendiğinde bitüm oranı arttıça stabilite değerinin yükseldiği görülmektedir. Bitüm oranının arttıkça stabilitenïn artma sebebi, agregalar arası boşlukların dolarak gelen yüklere karşı yükleri birbirlerine ileten agrega ve bitüm karışımı daha yüksek stabilite göstermiştir. Karışımların stabilite değerleri incelendiğinde en yüksek stabiliteyi volkanik cürufun filler malzeme olarak kullanıldığı karışımlarda olduğu, en düşük stabiliteyi ise kalkerin filler malzeme olarak kullanıldığı karışımlarda olduğu görülmüştür. 

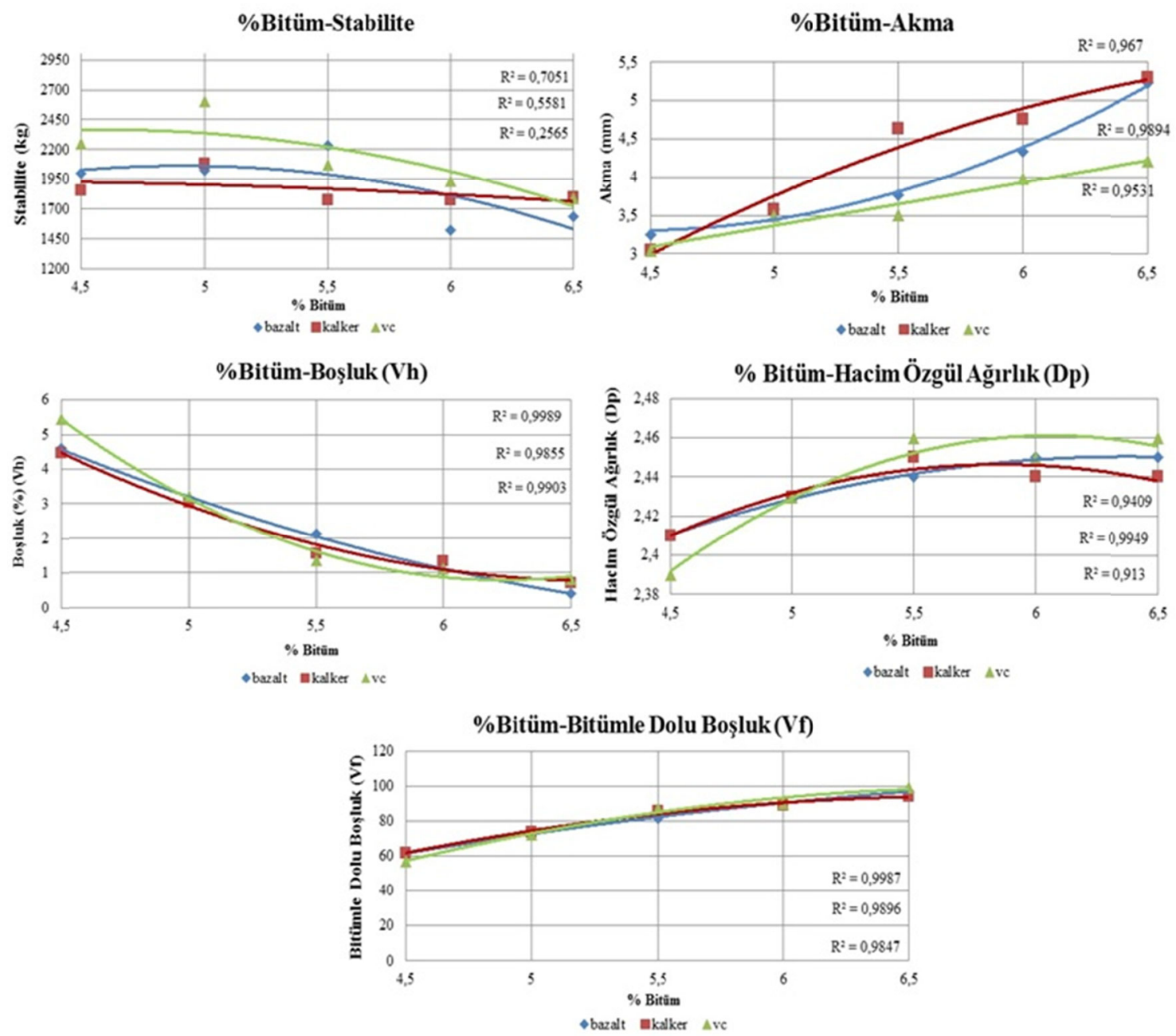

Şekil 4. Marshall stabilite deney sonucu grafikleri

\% Bitüm-Akma grafiği incelendiğinde bitüm oranı arttıkça akma değerinin de arttı̆̆ 1 görülmektedir. Bazalt ve kalker fillerin kullanıldı ̆̆ karışımlar benzer davranış gösterirken, volkanik cürufun kullanıldığı numunelerde akma miktarının daha az olduğu görülmektedir. $\mathrm{Bu}$ durumun volkanik cürufun gözenekli yapısından dolayı bitümü emmesinden kaynaklanmaktadır.

\% Bitüm-boşluk grafiği incelendiğinde bitüm oranı arttıkça karışımdaki boşluk oranı azalmıştır. Bu durum stabilite bakımından iyi olarak yorumlansa da optimum bitümden fazla kullanılacak bitüm miktarı kusma yapmakla birlikte bitümün fiyatından dolayı ekonomik olmayacaktır. Karayolları Teknik Şartnamesinde en uygun boşluk oran $1 \% 4$ olarak belirlenımiştir.

\%Bitüm-Hacim özgül ağırlık grafiği incelendiğinde bitüm miktarı arttıkça hacim özgül ağırlığın arttığ 1 görülmüştür. Kalker ve bazaltın kullanıldığı karışımlar yakın sonuçlar verirken, volkanik cürufun kullanıldığı karışımlarda $\% 4,5$ bitüm oranında daha düşük ve $\% 6,5$ bitüm oranında ise daha yüksek sonuç vermiștir. \%5 
bitüm oranında tüm karışımlar çok yakın sonuç vermiştir.

\%Bitüm-Bitümle dolu boşluk grafiği incelendiğinde tüm karışımların çok yakın sonuç verdiği görülmüştür. Bitüm oranı arttıkça bitümle dolu boşluğun arttığı tüm karışımlarda görülmüştür. Karayolları teknik şartnamesinde uygun bitümle dolu boşluk oranı \%70 olarak belirlenmiştir.

Şekil 4'te bulunan grafikler yardımıyla optimum bitüm yüzdesi belirlenmiştir. Maksimum stabilite, maksimum hacim özgül ağırlık (Dp), \%4 boşluk oranı (Vh) ve \%70 bitümle dolu boşluk (Vf) oranına denk gelen bitüm yüzdelerinin aritmetik ortalaması dikkate alınmıştır. Bazalt, kalker ve volkanik cürufun kullanıldığı karışımların optimum bitüm oranları Çizelge 9'da verilmiştir.

Çizelge 9. Optimum bitüm yüzdesi

\begin{tabular}{|c|c|c|c|}
\hline & Bazalt & Kalker & $\begin{array}{c}\text { Volkanik } \\
\text { cüruf }\end{array}$ \\
\hline Max stabilite & 5,0 & 4,5 & 4,5 \\
\hline Max Dp & 6,5 & 5,7 & 6,0 \\
\hline$\% 4 \mathrm{Vh}$ & 4,7 & 4,7 & 4,8 \\
\hline$\%$ 70 Vf & 5,0 & 5,0 & 5,0 \\
\hline $\begin{array}{c}\text { Optimum } \\
\text { bitüm }\end{array}$ & 5,30 & 5,00 & 5,07 \\
\hline
\end{tabular}

Çizelge 9 incelendiğinde bazalt fillerin kullanıldığ kontrol karışımın optimum bitüm yüzdesi \%5,30 olarak belirlenmiştir. Kalker ve volkanik cürufun kullanıldığı karışımlar kontrol fillerden daha düşük elde edilmiştir. Optimum bitüm yüzdesinin düşük olması maliyeti de düşürmektedir.

\section{SONUÇLAR}

$\mathrm{Bu}$ çalışmada karayollarında sıklıkla tercih edilen bazalt agregasıyla birlikte filler malzeme olarak kalker ve volkanik cürufun kullanılabilirliği araştırılmıştır. Çalışmada öncelikle agrega deneyleri, bitüm deneyleri ve daha sonra karışım gradasyonunun oluşturulmasıyla Marshall stabilite ve akma deneyi uygulanarak optimum bitüm belirlenmiştir. Çalışmada \%55 kaba agrega, \%39 ince agrega ve $\% 6$ filler kullanılmıştır. Bitümlü bağlayıcı olarak 50/70 penetrasyonlu bitüm tercih edilmiştir.

Agrega deney sonuçları incelendiğinde bazalt agregasının su emme sınır değeri aşması nedeniyle aşınma tabakasında kullanılması uygun görülmemiştir. Diğer sonuçlar incelendiğinde bazalt agregasının binder tabakasında kullanılmasının teknik şartname açısından daha doğru olduğu görülmüştür. Metilen mavisi sonuçları incelendiğinde bazalt ve kalker sınır değerleri aşmamıştır. Volkanik cürufun sınır değeri çok fazla aşması ilerde sorun oluşabileceğini göstermiştir.

Marshall stabilite ve akma deneyi sonuçları incelendiğinde düşük bitüm yüzdesinde en yüksek stabiliteyi volkanik cürufun kullanıldığı karışımlar vermiştir. Kalker fillerin kullanıldığı karışımlar, kontrol karışımlardan daha düşük stabilite sonuçları vermiştir. Üç numunenin optimum bitüm yüzdeleri kıyaslandığında en yüksek bitüm yüzdesi bazaltta elde edilirken, en düşük yüzde kalker fillerin kullanıldığı karışımlarda elde edilmiştir. Kalker ve volkanik cürufun kullanıldığı karışımların optimum yüzdeleri yakın sonuçlar verse de volkanik cüruflu karışımlar yüksek stabilite göstermiştir.

Sonuçlar genel olarak incelendiğinde bazalt agregasının binder tabakasında kullanılması önerilmiştir. Volkanik cürufun karayolları için önemli bir deney olan metilen mavisi deneyinde sınır değeri fazla aşması nedeniyle volkanik cürufun kullanıldığı karışımlar yüksek stabiliteye ulaşsa da ilerde oluşabilecek sorunlar öngörüldüğünden kullanımı önerilmemiştir. Kontrol bazalt filler karışımdan daha düşük stabiliteyi vermesine karşın; optimum bitüm yüzdesini düşürmesi ve bundan dolayı maliyetin düşmesi, metilen mavisi deney sonucunun sınır değeri aşmaması ve bundan dolayı kullanılması durumunda yolun kullanım ömrünü uzatması, bölgede kalker ocaklarının daha fazla bulunması ve bundan dolayı nakliye maliyetini düşürerek aynı zamanda ocaklardaki atık kalker tozlarının değerlendirilmesi kalker fillerin bitümlü sicak karışımlarda alternatif filler olarak kullanılabileceği sonucuna varılmıştır. 


\section{TEŞEKKÜR}

Bu çalışma Harran Üniversitesi Bilimsel Araştırma Projeleri (HÜBAP) tarafindan 19102 numaralı proje tarafından desteklenmiştir. Çalışmada kullanılan malzeme temini Şanlıurfa Büyükşehir Belediyesi, Beltaş A.Ş. ve Şanlı Asfalt A.Ş. tarafından yapılmıştır. Desteklerinden dolayı teşekkür ederiz.

\section{KAYNAKLAR}

1. Gray, L., Graham, I., 2015. Yakından TanıyınUlaşım. TÜBİTAK Popüler Bilim Kitapları, Ankara, 72.

2. Akgül Şeker, N.E., 2020. Bitümlü Sicak Karışımların Farklı İklim Şartlarında Bozulmasina Filler Etkisinin Değerlendirilmesi. Harran Üniversitesi, Fen Bilimleri Enstitüsü, Şanlıurfa. 100.

3. Clarkson, O.H., Hicks, G.R., 1982. Highway Engineering. New York, 730.

4. Prozzi, J.A., 2001. Modelling Pavement Performance by Combining Field and Experimental Data. Civil and Enviromental Engineering, University of California Berkeley, 139.

5. Gürer, C., Karaşahin, M., 2015. Hasarsız Deneylerle Bir Sathi Kaplamalı Yol Kesiminin Performans Değişiminin İncelenmesi. 11.Ulaştırma Kongresi, İstanbul. 213-220.

6. Aslan, D., Sarışık, A., 2018. Diyarbakır Yöresinde Bitümlü Sıcak Karışımlarda Bazalt, Kalker, Dere Malzemelerinin Karakteristik Özelliklerinin Karşılaştırılması. Harran Üniversitesi Mühendislik Dergisi. 3(3), 243-250.

7. Prowell, B.D., Zhang, J., Brown, E.R., 2005. Aggregate Properties and the Performance of Superpave-Designed Hot Mix Asphalt, National Center for Asphalt Technology. Auburn, AL. Transportation Research Board. Report, 539.

8. Turabi, A., Okucu, A., 2007. Balıkesir İli Yol Çalışmalarında Kullanılan Agregaların Özellikleri ve Şartnameye Uygunluğu.
Balıkesir Üniversitesi Fen Bilimleri Enstitüsü Dergisi, 9(1), 45-51.

9. Deniz, M.T., Lav, A.H., 2010. Asfaltlarda Bitümle Birlikte Granüler Sülfür Kullanımının Stabiliteye Etkisi. İTÜ Mühendislik Dergisi, 9(6), 137-148.

10. Eker, A.N., 2019. Bazalt ve Gabroların Bitümlü Sıcak Karışımlarda Agrega Olarak Kullanılabilirliğinin Değerlendirilmesi. Batman Üniversitesi, Fen Bilimler Enstitüsü, Batman, 109.

11. Çelik, O.N., Yonar, F., Ceylan, S., 2007. Bitümlü Sıcak Karışımların Performansına Filler Etkisi. 7.Ulaştırma Kongresi, 196-204.

12. D’Angelo, J.A., Harm, E.E., Bartoszek, J.C., Baumgardner, G.L., Corrigan, M.R., Cowsert, J.E., Newcomb, D.E., 2008. Warm-Mix Asphalt: European Practice. Washington, USA, FHWA.

13. Umar, F., Ağar, E., 1991. Yol Üstyapısı. İstanbul Teknik Üniversitesi İnşaat Fakültesi Matbaası, İstanbul, 339.

14. Tunç, A., 2007. Yol Malzemeleri ve Uygulamaları. Nobel Yayınevi, Ankara, 840.

15. Uluçay, M., 2000. Yollarda Pürüzlülük Sorunu. 3. Ulusal Asfalt Sempozyumu ve Sergisi, Ankara, 213-217.

16. OECD, 1984. Road Surface CharacteristicsTheir Interaction and Their Optimization. Road Transport Research, Paris.

17. Akbulut, H., İçağa, Y., Gürer C., 2003. Atık Agregaların Asfalt Yol Kaplamalarında Tekrar Kullanım İmkânı ve CEN Standartları. 3. Ulusal Kırmataş Sempozyumu, İstanbul.

18. Xiao, J., Kulakowski, B.T., El-Gindy, M., 2000. Prediction of Risk of Wet-Pavement Accidents: Fuzzy Logic Model. Transportation Research Record, 1717(1), 28-36.

19. Ishai, I., Graus, J., Sides, A., 1980. A Model for Relating Filler Properties to Optimal Behavior of Bituminous Mixtures. Proc. Association of Asphalt Paving Technologists. 49, 416-436.

20. Shahrour, A.M., Saloukeh, G.B., 1992. Effect of Quality and Quantity of Locally Produced Filler on Asphalt Mixtures in Dubai, Effects of Aggregates and Mineral Fillers on Asphalt 
Mixture Performance: ASTM STP 1147 , 187-208.

21. Su, Nan. Chen, J.S., 2002. Engineering Properties of Asphalt Concrete Made with Recycled Glass. National Yunlin University of Science and Technology, 259.

22. Yılmaz, M., Kök, B.V., 2008. Ferrokrom Cürufu Kullanımının Bitümlü Sıcak Karışımların Mekanik Özelliklerine Etkisi. Süleyman Demirel Üniversitesi Fen Bilimleri Enstitüsü Dergisi, 12(3), 186-194.

23. Arabani, M., Mirabdolazimi, S.M., 2011. Experimental Investigation of the Fatigue Behaviour of Asphalt Concrete Mixtures Containing Waste Iron Powder. Materials Science and Engineering. 528(10-11), 3866-3870.

24. Mazlum, M.S., 2014. Ekonomik Ömrünü Tamamlamış Asfalt Kaplamaların Kazınarak Bitümlü Sıcak Karışımlarda Yeniden Kullanılabilirliğinin Araştırılması. Karadeniz Teknik Üniversitesi, Fen Bilimleri Enstitüsü. Trabzon, 85.

25. Morova N., Terzi, S., 2015. Kolemanit Atıkların Sıcak Karışım Asfalt Betonda Agrega Olarak Değerlendirilmesi. Süleyman Demirel Üniversitesi Fen Bilimleri Enstitüsü Dergisi, 19(2), 8-15.

26. Nabiun, N., Khabiri, M.M., 2016. Mechanical and Moisture Suspectibility Properties of HMA Cointaining Ferrite for Their USA in Magnetic Asphalt. Construction and Building Materials, 113, 691-697.

27. Keskin, M., Karacasu, M., 2018. Atık Bor İçeren Asfalt Betonlarının Performanslarının Değerlendirilmesi. Frat Üniversitesi Mühendislik Bilimleri Dergisi, 30(2), 185-192.

28. Woszuk, A., Bandura, L., Franus, W., 2019. Fly Ash as Low Cost and Environmentally Friendly Filler and its Effect on the Properties of Mix Asphalt. Journal of Cleaner Production.

29. Beycioğlu, A., Kaya, O., Yıldırım, Z.B., Bağrıaçı, B., Dobiszewska, M., Morova, N., Çetin, S., 2020. Use of GRP Pipe Waste Powder as a Filler Replacement in Hot-Mix Asphalt. Materials, 13(20), 4630.

30.2020. Karayolları Genel Müdürlüğü. http:// www.kgm.gov.tr//. Erişim: Kasım 2020.
31. Karayolları Genel Müdürlüğü, 2013. Karayolu Teknik Şartnamesi, Ankara, 431.

32. TS EN 1097-6, (2013). Agregaların Mekanik ve Fiziksel Özellikleri için Deneyler-Bölüm 6: Tane Yoğunluğunun ve $\mathrm{Su}$ Emme Oranının Tayini, Ankara.

33. TS EN 1097-2, 2010. Agregaların Mekanik ve Fiziksel Özellikleri için Deneyler-Bölüm 2: Parçalanma Direnci Tayini için Yöntemler, Ankara.

34. TS EN 12697-11, 2012. Bitümlü KarışımlarDeney Metotları-Sıcak Karışımlı Asfalt için Bölüm 11: Agrega ve Bitüm Arasındaki Bağlanmanın Tayini, Ankara.

35. ASTM D4644-87, 1998. Standard Test Method for Slake Durability of Shales and Similar Weak Rocks. 4.

36. TS EN 1367-2, 2010. Agregaların Termal ve Bozunma Özellikleri için Deneyler-Bölüm 2: Magnezyum Sülfat Deneyi, Ankara.

37. TS EN 933-9+A1, (2014). Agregaların Geometrik Özellikleri için Deneyler-Bölüm 9: İnce Tanelerin Tayini-Metilen Mavisi Deneyi, Ankara.

38. Gamble, J.C., 1971. Durability-Plasticity Classification of Shales and Other Argillaceous Rocks. Ph. D., Thesis, University of Illinois, 159.

39. TS EN 15326+A1, 2010. Bitümler ve Bitümlü Bağlayıcılar-Yoğunluk ve Özgül Kütle Tayini -Kapiler Kapaklı Piknometre Yöntemi, Ankara.

40. TS EN 1426, 2015. Bitüm ve Bitümlü Bağlayıcılar-İğne Batma Derinliği Tayini, Ankara.

41. TS EN 1427, 2015. Bitüm ve Bitümlü Bağlayıcılar- Yumuşama Noktası TayiniHalka ve Bilye Yöntemi. Ankara.

42. TS EN ISO 2592, 2017. Petrol ve İlgili Ürünler -Parlama ve Yanma Noktasının TayiniCleveland Açık Kap Yöntemi, Ankara.

43. TS EN 13589, 2018. Bitümler ve Bitümlü Bağlayıcılar-Kuvvet Uygulamalı Süneklik Yöntemiyle Modifiye Bitümün Gerilme Özelliklerinin Belirlenmesi, Ankara.

44. ASTM D6927-15, 2015. Standard Test Method for Marshall Stability and Flow of Asphalt Mixtures. 7. 
